\title{
ENTREVISTA
}

\section{A través de la lente de la cultura urbana}

\author{
Elisa Pritzker ${ }^{1}$ \\ Artista y Curadora independiente \\ www.elisapritzker.com
}

DOI: http://dx.doi.org/10.5377/koot.v0i8.5871

URI: http://hdl.handle.net/11298/385

\section{Resumen}

Elisa Pritzker realiza en marzo de 2017 una entrevista al artista plástico salvadoreño Karlos Cárcamo, radicado en Nueva York, publicada en la columna "La Esquina de las Artes" [The Corner of the Arts] que aparece en La Voz [Bard College] y ABClatino Magazine [bilingüe].

La familia de Cárcamo emigró de El Salvador a principios de la década de 1970. Él estudió en la Escuela de Artes Visuales y en el Hunter College, ambos de Nueva York y desde 2007 trabaja en el Departamento de Enmarcado del Museo de Arte Moderno (MoMA), donde se encarga de verificar las condiciones de los marcos de las piezas que van a ser exhibidas y, en caso de que sea necesario, construir nuevas y realizar labores de conservación. En 2009 viajó por primera vez a El Salvador para participar en la exposición colectiva "Zona de Trueque", en el Museo de Arte (Marte), con una escultura elaborada con discos de vinil llamada "A Concrete Movement" (Un movimiento concreto) ${ }^{2}$.

Palabras clave: Arte, migración, museo, museología, memoria histórica, identidad, conservación, escultura.

\begin{abstract}
In March 2017, Elisa Pritzker interviewed the Salvadoran plastic artist Karlos Cárcamo, who lives in New York; the interview was published in the column "The Corner of the Arts" that appears in La Voz (Bard College) and ABClatino (Bilingual)
\end{abstract}

\footnotetext{
${ }^{1}$ Elisa Pritzker, es artista y curadora independiente. Sus escritos pueden ser leídos en www. elisapritzker.com

2 “Esculturas del salvadoreño Karlos Cárcamo se exhiben en Nueva York", publicada en El Diario de Hoy. Disponible en el enlace: http://www.elsalvador.com/vida/177764/esculturasdelsalvadoreno-karlos-carcamo-se-exhiben-en-nueva-york/
} 
Cárcamo's family emigrated from El Salvador in the early 1970s. He studied at the School of Visual Arts and Hunter College both located in New York.

Furthermore, since 2007 he has worked in the Department of the Framing of the Museum of Modern Art (MOMA) where he is in charge of verifying the conditions of the frames of the pieces that are going to be exhibited. When necessary, he even constructs new ones and carries out conservation work. In 2009 he traveled for the first time to El Salvador to participate in the collective exhibition "Barter Zone", at the Museum of Art (MARTE) by displaying a sculpture made with vinyl records called "A Concrete Movement".

Keywords: Art, migration, museum, museology, historical memory, identity, conservation, sculpture.

\section{Sumario:}

El artista Karlos Cárcamo tiene una Maestría en Bellas Artes de Hunter College en Nueva York. Ha expuesto sus obras en el Museo de Brooklyn, Museo del Bronx, MoMA PS1, Museo del Barrio, Museo de Jersey City y el Centro de Arte Contemporáneo de Aljira; Su trabajo ha sido revisado en publicaciones que incluyen, Arte in América, New York Times, New York Daily News, y el Village Voice, entre otras publicaciones. www.karloscarcamo.com

\section{EP. Karlos, en tus obras usas un lenguaje abstracto. ¿Cómo describes tu trabajo?}

KC. Describo mi trabajo como una exploración formal sobre el lenguaje codificado y la historia del arte abstracto a través de un proceso que combina referencias culturales altas y bajas. Estas referencias provienen de una variedad de fuentes diversas tomadas de o como me gusta llamarlo "muestreado" de la historia del arte modernista y la cultura urbana. Utilizo este enfoque conceptual para crear un trabajo que re-contextualiza y desafía la naturaleza, la historia y el impulso a la pureza que se encuentran a menudo en el arte abstracto y específicamente en la pintura abstracta.

\section{EP. ¿Cómo influyen tus raíces en su arte?}

KC. Creo que cuando se trata de mis raíces como una influencia que realmente ha desarrollado círculo completo en el tiempo. Vine a aprender sobre la abstracción latinoamericana después de terminar la escuela de posgrado en el año 2000. En el momento en que yo estaba en la escuela, la historia del arte estaba siendo enseñada a través de una perspectiva histórica del arte occidental centrada en el euro. El cubismo, el surrealismo a través del expresionismo abstracto, el minimalismo, etc. No fue hasta que tomé un viaje a México en 2002 que me di cuenta de un linaje alternativo. Eso también viene de Europa en la forma del constructivismo ruso, Bauhaus, al arte concreto del latinoamericano y al arte 


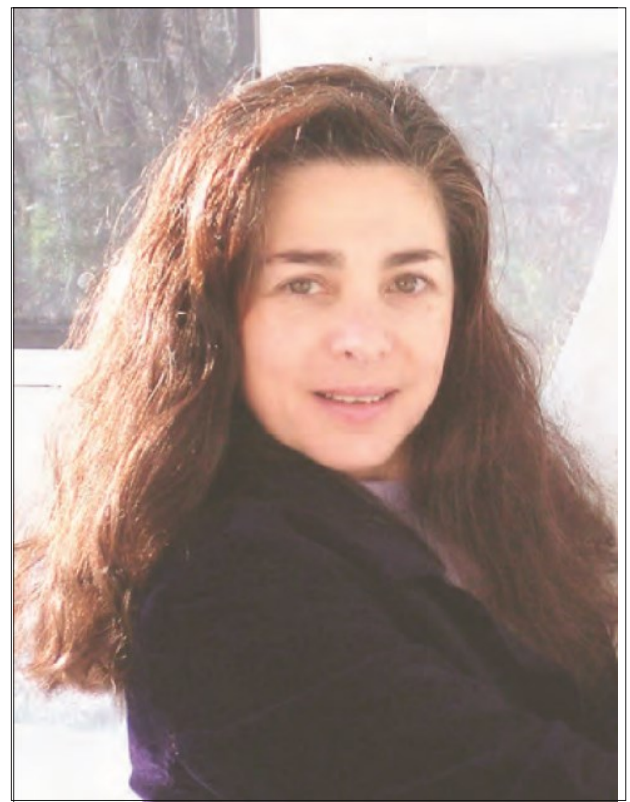

Elisa Pritzker

neoconcreto. Artistas como Lygia Clark (brasileña, 1920-1988) para nombrar a un artista, han influido en cómo pienso y veo mi propia práctica artística de América Latina. Siento que se añade a mi comprensión de donde mi trabajo encaja dentro de este marco histórico. También ha llevado a una reconexión y el interés en la historia del arte de mi propio país de nacimiento, El Salvador, y su rica escena artística contemporánea.

\section{EP. Trabajas en el MoMA [Museo de Arte Moderno de Nueva York], ¿cómo coordinas tu trabajo en el museo con tu estudio?}

KC. Trabajar a tiempo completo para una institución como el MoMA es una bendición de muchas maneras, pero exigente como es cualquier empleo a tiempo completo. Trato de encontrar un equilibrio que permita tiempo en el estudio. Tengo que maximizar cómo uso mí tiempo especial viviendo en el Valle de Hudson siendo que mi viaje diario es aproximadamente 2 horas de puerta en puerta. Trato de usar este tiempo de forma productiva para elaborar ideas para cuando llegue a casa $u$ organizar mi trabajo e imágenes en mi portátil.

\section{EP. ¿Dónde estás en tu carrera como artista?}

KC. Tendría que decir que estoy en la mitad de la carrera. Habiendo estado fuera de la escuela desde 2000. Trabajo con una galería de arte del Lower East Side llamada Galería Hionas que representa mi trabajo en la ciudad de Nueva York. 


\section{EP. ¿Qué proyecto (s) tiene en un futuro próximo?}

KC. A medida que escribo estas respuestas, trabajo actualmente en el Museo Picasso, Málaga, España como parte de la desinstalación de la retrospectiva De Joaquín Torres-García (Uruguay, 1874-1949). La muestra fue organizada por el MoMA en colaboración con el Museo Picasso Málaga y la Fundación Telefónica y comisariada por Luis Pérez-Oramas, conservador del arte latinoamericano en el Museo de Arte Moderno de Nueva York. En cuanto a mi propio trabajo, tengo esculturas a la vista en una exposición titulada Hip-Hop Utopia: Cultura + Comunidad en la Galería de Arte Dineen Hull de Jersey City. A finales de febrero tendré trabajo en una feria de arte de la ciudad de Nueva York llamada "Spring / Break Art Fair" curada por el crítico de arte y artista Chris Bors y estoy trabajando en dibujos preliminares para un gran mural que se instalará en el Museo De Arte de El Salvador (MARTE) más tarde en el año organizado por el artista salvadoreño Walterio Iraheta.

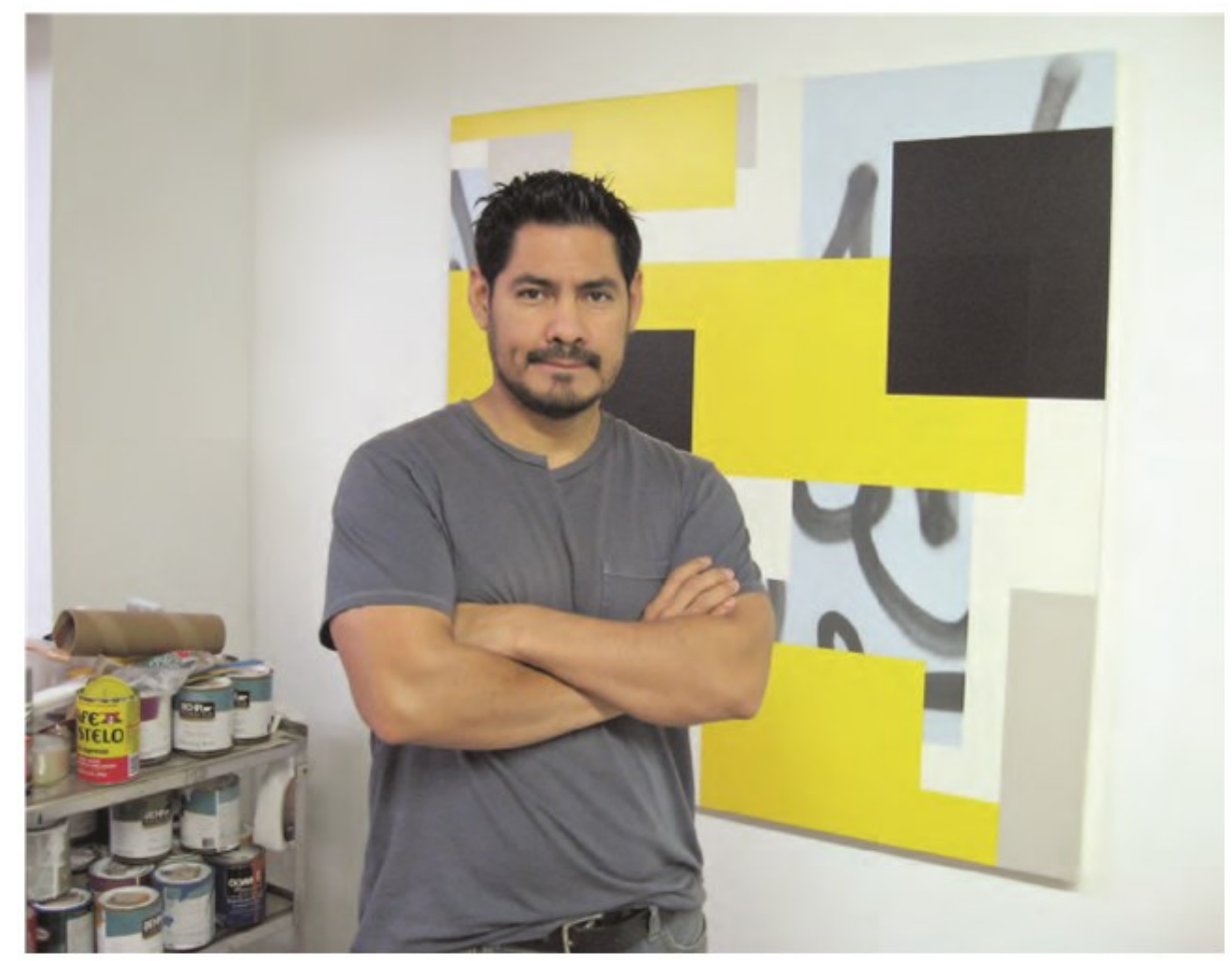

Karlos Cárcamo.

Foto cortesía del artista. 


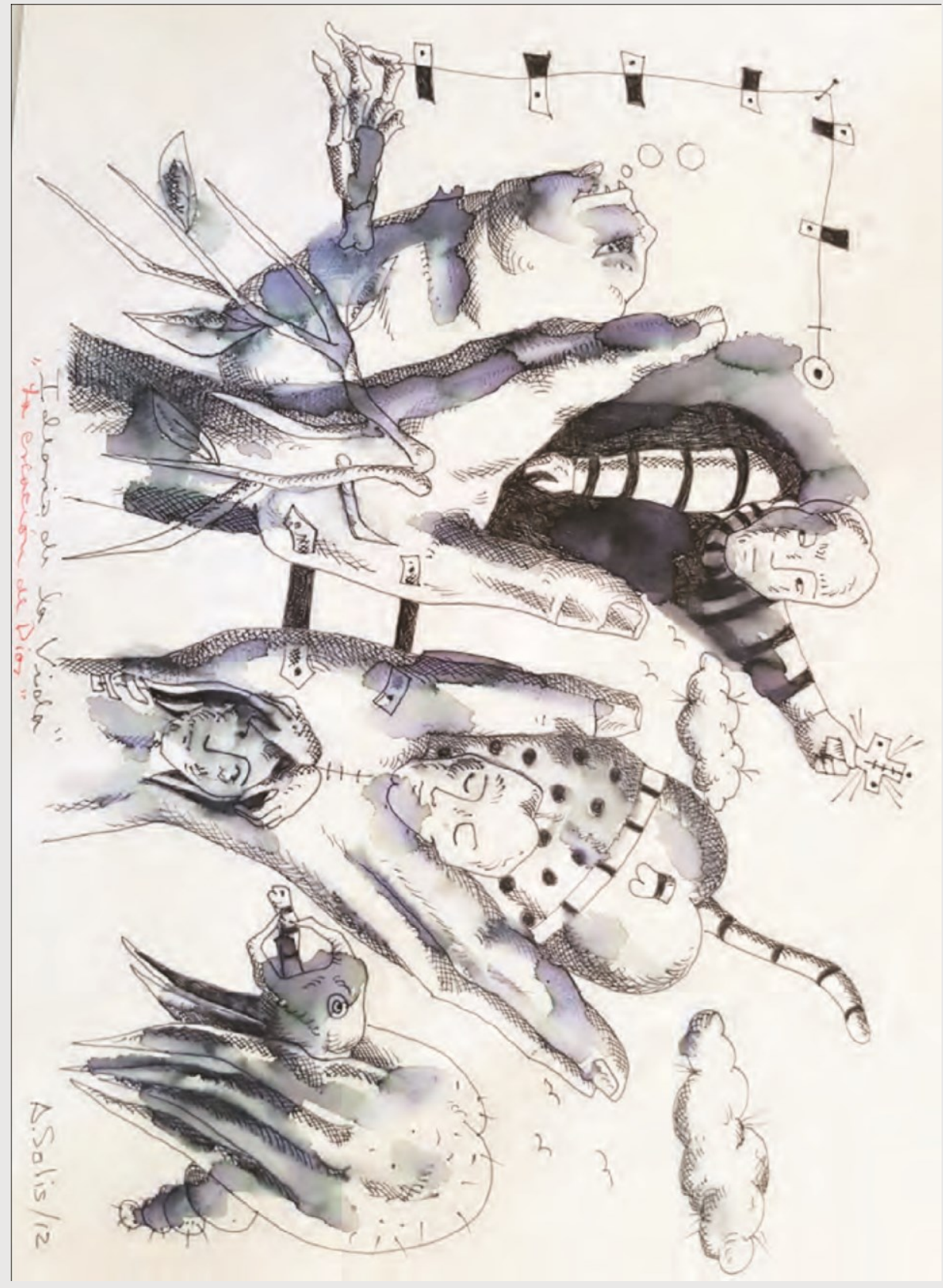

Armando Solis 